học cơ sở Minh Trí tại Thành phố Trà Vinh nói riểng cũng như học sinh Trung học cơ sở nói chung về hành vi sử dụng mạng xã hội một cách phù hợp để không ảnh hưởng đến kết quả học tập cũng như cuộc sống của học sinh để góp phần làm nâng cao kết quả học tập của học sinh. Ngoài ra, cần đẩy manh chiến lược truyền thông giáo dục sức khỏe để giảm thiểu tỷ lệ suy dinh dưỡng ở học sinh.

\section{TÀl LIÊU THAM KHẢO}

1. Lê Minh Công (2013), "Tình trạng nghiện internet ở hoc sinh trung hoc cơ sở tai thành phố Biên Hòa tỉnh Đồng Nai", Tạp chí Khoa hoc tr1-13.

2. Nguyễn Thi Minh Ngọc (2017), "Thực trạng nghiện Internet của học sinh trường Trung học phổ thông Hải Hậu, tỉnh Nam Đinh năm 2017 và môt số yểu tố liên quan", Tạp chí Y học dự phòng.

3. Trân Minh Trí (2016), "Thực trạng sử dụng Internet và những tác đống của Internet đến sinh viên trường Đại học Nông lâm TP.HCM", Tạp chí
Nông lâm học, Đại học Nông lâm TP.HCM, tr1-11.

4. Kilic $\mathbf{M}$ and et al (2016), "Internet Addiction in High school Students in Turkey and Multivariate Analyses of the Underlying Factors", ] Addict Nurs, doi: 10.1097/JAN.0000000000000110.

5. Ozalp EKINCI and et al (2014), "Association between Internet use and sleep Problems in Adolescents", Noro Psikiyatr Ars, doi: 10.4274/ npa.y6751.

6. Jian $X u$ and et al (2012), "Personal characteristics related to the risk of adolescent internet addiction: a survey in Shanghai, China", BMC Public Health, doi:10.1186/1471-2458-12-1106.

7. Milani Luca and et al (2009), "Quality of interpersonal relationships and problematic internet use in adolescence", Cyberpsychol Behav, doi: $10.1089 / c p b .2009 .0071$.

8. Tran Xuan Bach and et al (2017), "A student on the influence of internet addiction and online interpersonal on health-related quality of life in young Vietnamese", BMC Public Health , doi: 10.1186/s12889-016-3983-z.

\title{
CÁC CẤP Độ KÉO DÀI TRỤ MŨI TRONG TẠO HÌNH MŨI TRÊN BỆNH NHÂN DI CHỨNG KHE HỞ MÔI VÒM
}

\author{
Vũ Thị Dung ${ }^{1}$, Phạm Kiến Nhật ${ }^{2}$, Phạm Tuấn $A_{n h}{ }^{2}$, \\ Lưu Phương Lan², Đỗ Tuấn Ngọc ${ }^{2}$, Hoàng Tuấn Anh ${ }^{1}$
}

\section{TÓM TẮT}

Mục tiêu của bài báo này là trình bày một cách tiễ̂́p cận theo các cấp độ để kéo dài trụ mũi trong phẫu thuật tạo hình mũi trên bệnh nhân di chứng khe hở môi - vòm dựa trên các đắc điểm nhân trắc học. Đây là nghiên cứu thuần tập hồi cứu trên các bênh nhân điều trị tại Bệnh viện Đại học Y Hà Nội từ năm 2017 đến năm 2021 . 18 bếnh nhân với biến dang môi - mũi di chứng khe hở mổi vòm được phẫu thuật tạo hình mũi với 4 phương pháp tiếp cận kéo dài trụ mữi gồm: vạt dồn đẩy $V-Y$ (10 bệnh nhân), vạt xoay đẩy theo Millard (3 bệnh nhân), vạt folked (3 bệnh nhân) và vạt Abbé ( 2 bệnh nhân). Kết quả được đánh giá bằng cách sử dụng hệ thống chấm điểm theo bảng câu hỏi "Đánh giá kết quả tạo hình mũi" (ROE) và hệ thống chấm điểm Mortier. 4 thông số đo lường nhân trắc học được thu thập để định lượng và đánh giá khách quan. Thời gian theo dõi trung bình là 9 tháng. Mức độ biến dạng ban đầu trung bình là 22,72 $\pm 5,99$ điểm và kết quả sau phẫu thuật là $72,58 \pm 11,45$ điểm theo bộ câu hỏi "Đánh giá kết quả tạo hình mũi (ROE)". Phương pháp tiếp cận kéo dài trụ mũi theo các cấp độ

\footnotetext{
${ }^{1}$ Bệnh viện Đại học Y Hà Nội

${ }^{2}$ Trường Đại học Y Hà Nội

Chịu trách nhiệm chính: Vũ Thị Dung

Email: vuthidung.ptth@gmail.com

Ngày nhận bài: 24/8/2021

Ngày phản biện khoa học: 22/9/2021

Ngày duyệt bài: 3/10/2021
}

đã cho thấy kết quả tốt, tỷ lệ bệnh nhân hài lòng cao và tỷ lệ biến chứng thấp.

Tư khóa: Khe hở môi - vòm, tạo hình mũi, kéo dài trụ mũi.

\section{SUMMARY \\ GRADUATED APPROACH TO LENGTHENING COLUMELLA IN CLEFT RHINOPLASTY}

The purpose of this article was to present a graduated approach to lengthening columella in cleft rhinoplasty based on antropometric features. This was a retrospective cohort study of patients treated at the Hanoi Medical University Hospital from 2017 to 2021. 18 patients underwent rhinoplasty with four approaches include: $\mathrm{V}-\mathrm{Y}$ plasty (10 patients), rotationadvancement flap (3 patients), Forked flap (3 patients) and Abbé flap (2 patients). Outcomes were assessed by using a Rhinoplasty Outcome Evaluation (ROE) questionnaire and the Mortier scoring system. 8 parameters of anthropometric measurement were collected for objective evaluation. Of the 18 patients enrolled in the study, 10 were women and 8 were men. Mean follow-up period was 9 months. The average degree of initial deformity was $22.72 \pm 5.99$ and postoperative result was $72.58 \pm 11.45$ according to the "Rhinoplasty Outcome Evaluation (ROE)". The graduated approach has shown excellent outcomes, a high rate of patient satisfaction, and a low rate of complication.

Keywords: Cleft lip and palate, rhinoplasty, columella lengthenning. 


\section{I. ĐĂT VẤN ĐỀ}

Một trong những biến dạng đặc trưng của bệnh nhân khe hở môi - vòm miệng bẩm sinh, đặc biệt là khe hở môi hoàn toàn hai bên là trụ mũi ngắn hoăc thâm chí không có tru mũi. Nguyên nhân có thể là do rối loạn hình thái nguyên phát, thường là giảm sản và biến dạng do hậu quả thứ phát của phẫu thuật thì đâu. Những bệnh nhân này thường có một tập hợp biến dang dễ thấy và đăc trưng: đâu mũi rộng và phẳng, được neo xuống môi trên, lỗ mữi lớn, cánh mũi loe ra như mũi cừu. Di tât này có xu hướng dễ thấy hơn theo thời gian, khi đâu mũi tẹt và lỗ mũi loe ra ngày càng nhiêu khi khung xương mũi phát triển ${ }^{1}$. Hầu hết các nỗ lực để tái tao hoăc kéo dài tru mũi ở lần phẫu thuât đâu tiên ít cho kết quả khả quan, chủ yếu do thiếu tổ chức phù hợp ở giai đoạn này. Có nhiêu phương pháp kéo dài trụ mũi khác nhau tùy thuộc vào mức độ biến dạng mũi. Để tái tạo một trụ mũi đủ chiều dài với hình dáng tự nhiển là một thách thức của phẫu thuật; điều này có lẽ xuất phát từ thực tế là trụ mũi sau tái tạo thường dày và bị co rút laii.Để nẩng cao khả nằng lập kế hoạch điều trị và tiên lượng kết quả, chúng tôi thực hiện nghiên cứu "Đánh giá kết quả kéo dài trụ mũi theo các câp độ trong tạo hinh mữ ở bệnh nhân di chứng khe hở môi - vòm".

\section{II. ĐỐI TƯỢNG VÀ PHƯƠ'NG PHÁP NGHIÊN CỨU}

2.1. Đối tượng nghiên cứu: Gồm 18 bệnh nhân được chẩn đoán biến dạng môi - mũi di chứng khe hở môi - vòm phẩu thuật tại Bệnh viện Đại học Y Hà Nôii từ 2017- 2021.

2.2. Phương pháp nghiên cứu

- Thiết kế nghiên cứu: Phương pháp nghiên cứu thuân tâp hồi cứu.

\section{- Qui trình phấu thuật}

Bệnh nhân được gây mê nội khí quản. Tất cả bệnh nhân được nâng sống mũi bằng silicon; dựng trụ mũi với Medpor hoăc ghép sụn vách; tạo hình đâu mũi với sụn vành tai hoặc khâu định hướng sụn cánh mũi. Kéo dài trụ mũi được thực hiện bằng một trong bốn phương pháp theo mức độ tăng dân tương ứng với độ ngắn của trụ mũi: nhẹ, trung bình, nặng và rất nặng.

Vat dồn đẩy V-Y được chỉ định cho những trường hợp tăng chiêuu dài trụ mũi dưới $2 \mathrm{~mm}$. Thiết kế vạt theo hình chữ $\mathrm{V}$ với cuống là trụ mũi ban đầu, đỉnh chữ V nằm ở chân trụ mũi. Vạt có thể bao gồm cả phân trung tâm của mấu môi tùy theo mức độ thiếu hụt chiều dài trụ mũi. Vạt được nâng lển cùng với tổ chức dưới da. Đường rạch phía bên kéo dài dọc 2 bên trụ mũi tới vách mũi và vòm cánh mũi 2 bên để giải phóng hoàn toàn trụ mũi và tăng khả năng di động vạt, đồng thời tạo đường vào thích hợp cho các can thiệp chỉnh sửa các biến dạng khung sun mũi, đăt các mảnh ghép dựng trụ mũi. Vạt được dịch chuyển lên phía trên theo nguyên tắc của vạt dồn đây $\mathrm{V}$ Y. Sau khi đóng vết mổ, đường sẹo chữ Y nằm trên đường giữa. (Hình $1 \mathrm{~A}$ )

Vạt xoay đẩy theo Millard được chỉ định cho những trường hợp tăng chiều dài trụ mũi từ $2-3 \mathrm{~mm}$. Thiết kế vạt theo đường rạch mũi mơ bao gồm đường rạch bờ cánh mũi và ngang trụ mũi, kéo dài xuống dưới môi theo thiết kế tạo hình môi Millard. Vạt chữ $\mathrm{C}$ được xoay lên trụ mũi hoăc xoay về phía nền mũi tùy theo kiểu biến dạng. (Hình 1B)

Vạt Forked được chỉ định cho những trường hợp tăng chiều dài trụ mũi từ 3-5mm. Trong kỹ thuật này, hai ngành của vạt được thu hoạch từ hai bên của mấu môi dưới dạng vat hình chữ "V", từ trụ mũi kéo dài xuống các điểm cao nhất của cung Cupid. Tùy vào nhu câu huy động tổ chức, vạt có thể bao gôm cả sẹo môi từ lân phẫu thuật trước. Để nâng cao đâu mũi đây đủ, các vết rạch kéo dài qua qua 2 bờ trụ mũi tới tận vách mũi, giải phóng hoàn toàn vạt và trụ mũi khỏi sự gắn kết với vách ngăn mũi. Qua đường mở này, việc chỉnh sưa các biến dạng của sụn cánh mũi và vách mũi được thực hiện. Hai ngành của vạt được khâu lại với nhau trên đường giữa, các vết rạch được đóng lại, nhờ đó trụ mũiđược kéo dài. (Hình $1 \mathrm{C}$ và $1 \mathrm{D}$ )
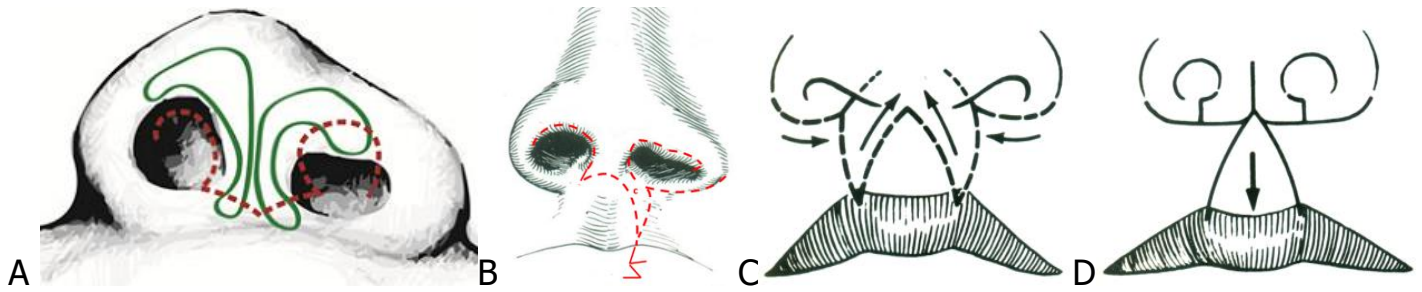

Hình 1. A- Đường mổ tạo hỉnh mũi mở và kéo dài trụ mũi với tạo hình $V-Y$ ở vùng nhân trung. B-Tạo hinh mũi mở với vạt xoay đây ở môi theo Millard, tạo hinh chữ $Z$ ở vùng môi đỏ nếu cần. C,D-Vạt folked kéo dài trụ mưi. 
Vạt Abbé được chỉ định cho những trường hợp tăng chiều dài trụ mũi trên $5 \mathrm{~mm}$. Ở môi trên, da nhân trung liên tục với trụ mũi được dùng để kéo dài trụ mũi. Sẹo và cớ vòng môi được cắt để nhận vạt từ môi dưới bao gồm cả da, cơ và niêm mạc. Vạt Abbé được thiết kế với kích thước phù hợp với nhân trung, có cuống nuôi là động mạch vòng môi. Phần cuống chứa lượng nhỏ niêm mạc, cơ ở mặt trên sau của môi dưới. Với cuống nhỏ, vạt dễ dàng xoay lên trên mà không làm biến dạng mô quanh cuống và không tác động xấu đến nguồn cấp máu. Phần niêm mạc mặt trước xương hàm trên và của mấu môi được bảo tổn để tạo hình ngách tiền đình. Vạt Abbé sau đó được đưa vào nơi nhận và đóng theo từng lớp. Vạt được cắt cuống sau 2 tuần đồng thời với chỉnh sửa môi đỏ.
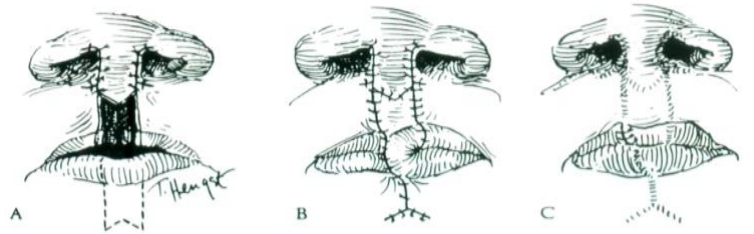

Hinh 2. A- Mấu môi ban đầu được đây lên làm trụ mũi. $B$ - Vạt Abbe từ môi dưới xoay lên tạo hình nhân trung. C-Cắt chân nuôi vạt sau 2

tuần. (From Cronin, T. D., and Upton, J.:

Lengthening of the short columella associated with bilateral cleft lip. Ann. Plast. Surg., 1:75, 1978)

- Đánh giá kết quả. Việc đánh giá được thực hiê̂n ở 3 thời điểm: trước phẫu thuật, ngay sau phấu thuật và thời điểm khám lại sau ít nhất 3 tháng.
Tất cả các bệnh nhân được chụp ảnh ở 3 tư thế: thẳng, nghiêng và chếch dưới (góc nhìn từ nền mũi, với hình chiếu đầu mũi nằm giữa khoảng cách từ góc mắt trong đến cung mày). Thông qua tư liệu hình ảnh, 4 chỉ số nhân trắc về tỷ lệ cân đối mũi-mặt được gián tiếp đo đạc. (Hinh 3)

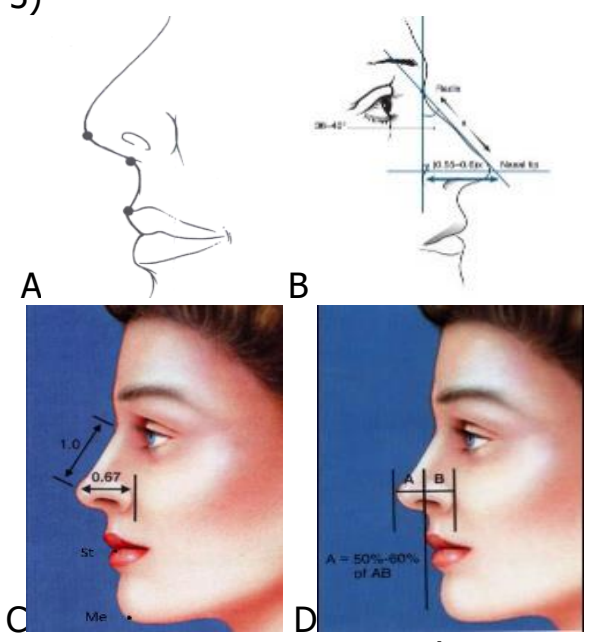

Hinh 3. Các thông số nhân trắc đánh giá cân đối mũi-mặt. A- tỷ lệ chiều dài môi trên (từ điểm chân trụ mũi tới ranh giới môi trên trắng-đỏ): độ nhô mũi (từchân trụ mũi tới đầu mũi) $=1$ (Simon analysis); B- Tỷ lệ độ nhô mũi (chân cánh mũi tới đâu mũi): chiều dài mũi (gốc mũi tới đầu mũi) = 0,55-0,6 (Goode analysis); C- Tỷ lệ chiều dài mũi:chiều cao tầng dưới mặt (chân trụ mũi tới dưới cằm) $=1 ; \mathrm{D}$ - Đường thẳng đứng qua đỉnh môi trên chia mũi thành hai phần trước sau với tỷ lệ 1/2 (Gunter and Rohrich analysis).

Bảng 1. Bảng câu hỏi đánh giá kết quả tạo hình mũi ROE?.

\begin{tabular}{|c|c|c|c|c|c|}
\hline Câu hỏi & $\begin{array}{c}\text { Hoàn toàn } \\
\text { không }\end{array}$ & $\begin{array}{c}\text { Mốt } \\
\text { chút }\end{array}$ & $\begin{array}{c}\text { Chấp nhận } \\
\text { được }\end{array}$ & $\begin{array}{c}\text { Có } \\
\text { Thích hình dáng mũi? }\end{array} \quad 0 \quad \begin{array}{c}\text { Hoàn toàn } \\
\text { đồng ý }\end{array}$ \\
\hline Thở dê dàng qua mũi?? & 0 & 1 & 2 & 3 & 4 \\
\hline Người thân thích mũi của bạn? & 0 & 1 & 2 & 3 & 4 \\
\hline Hạn chế giao tiếp xã hội? & 0 & 1 & 2 & 3 & 4 \\
\hline Tự tin với mũi của mình? & 0 & 1 & 2 & 3 & 4 \\
\hline Mong muốn phâuu thuật sửa chữa & 0 & 1 & 2 & 3 & 4 \\
\hline
\end{tabular}

Kết quả phấu thuật cũng được đánh giá bằng cách sử dụng bảng câu hỏi "Đánh giá kết quả tạo hình mũi" (ROE) ${ }^{2}$ và hệ thống chấm điểm Mortier ${ }^{3}$.Mỗi câu hỏi cho điểm từ 0 đến 4 . Điểm tối đa là 24 với 6 câu hỏi. Tổng điểm được quy chiếu sang hệ điểm 100. Đánh giá thời điểm trước và sau mổ.

Bảng 2. Hệ thống chấm điểm Mortier đánh giá biến dạng mũi ở bệnh nhân khe hở môi ${ }^{3}$

\begin{tabular}{|c|c|c|c|c|c|}
\hline $\begin{array}{c}\text { Thiếu phần } \\
\text { trên bờ lỗ } \\
\text { mũi }(0,5)\end{array}$ & $\begin{array}{c}\text { Cánh mũi } \\
\text { vị trí cao } \\
(0,5)\end{array}$ & $\begin{array}{c}\text { Nền mũi } \\
\text { hẹp }(0,5)\end{array}$ & $\begin{array}{c}\text { Nền trụ mũi } \\
\text { rộng }(0,5)\end{array}$ & $\begin{array}{c}\text { Cánh mũi vị } \\
\text { trí thấp }(0,5)\end{array}$ & $\begin{array}{c}\text { Cánh mũi } \\
\text { bẹt, thiểu } \\
\text { săn }(3)\end{array}$ \\
\hline
\end{tabular}




\begin{tabular}{|c|c|c|c|c|c|}
\hline $\begin{array}{c}\text { Lệch vách } \\
\text { ngăn (2) }\end{array}$ & $\begin{array}{c}\text { Nền mũi } \\
\text { rộng }(0,5)\end{array}$ & $\begin{array}{c}\text { Nền trụ mũi } \\
\text { hẹp }(0,5)\end{array}$ & $\begin{array}{c}\text { Thừa bao } \\
\text { phủ cánh } \\
\text { mũi }(0,5)\end{array}$ & $\begin{array}{c}\text { Thiếu bao } \\
\text { phủ cánh } \\
\text { mũi }(0,5)\end{array}$ & $\begin{array}{c}\text { Trú mũi } \\
\text { ngắn }(0,5)\end{array}$ \\
\hline
\end{tabular}

\section{KẾT QUẢ NGHIÊN CỨU}

Nghiên cứu thực hiện trên 18 bệnh nhân với 10 bệnh nhân nữ và 8 bệnh nhân nam; tuổi trung bình là 22 tuổi. Trong đó có 6 bệnh nhân khe hở môi hai bên và 12 bệnh nhân khe hở môi một bên. Các bệnh nhân khe hở môi 1 bên được phẫu thuật với tạo hình $\mathrm{V}$-Y (10 bệnh nhân) và vạt xoay đẩy ( 2 bệnh nhân). Các bệnh nhân khe hở môi hai bên được phẫu thuật với tạo hình forked flap (4 bệnh nhẩn) và vạt Abbe ( 2 bệnh nhân).

Bảng 3. Thay đổi các chi số nhân trắc của mưi trước và sau phẫu thuật

\begin{tabular}{|c|c|c|}
\hline $\begin{array}{c}\text { Chỉ số trung bình } \\
\text { (n=18) }\end{array}$ & $\begin{array}{c}\text { Trước } \\
\text { phẫu } \\
\text { thuật }\end{array}$ & $\begin{array}{c}\text { Sau } \\
\text { phẫu } \\
\text { thuật }\end{array}$ \\
\hline $\begin{array}{c}\text { Tỷ lệ chiều dài môi trên: } \\
\text { độ nhô mũi }\end{array}$ & 0,69 & 0,65 \\
\hline $\begin{array}{c}\text { Tỷ lệ độ nhô mũi: chiều } \\
\text { dài mũi }\end{array}$ & 0,46 & 0,53 \\
\hline $\begin{array}{c}\text { Tỷ lệ chiều dài mũi: chiều } \\
\text { cao tâng dưới mặt }\end{array}$ & 0,8 & 0,876 \\
\hline $\begin{array}{c}\text { Tỹ lệ phâ̂n trước trư mũi: } \\
\text { chiều cao mưi }\end{array}$ & 0,43 & 0,47 \\
\hline
\end{tabular}

Thời gian theo dõi trung bình là 9 tháng. Mức độ biến dạng ban đầu trung bình là 24,7 $\pm 5,99$ điểm và kết quả sau phẫu thuật là $72,58 \pm 11,45$ điểm theo thang điểm "Đánh giá kết quả tạo hình mũi (ROE)". Thang điểm Mortier đánh giá mức độ nặng của biến dạng cải thiện rõ rệt từ trước mổ $4.1 \pm 2.0$, sau mổ giảm còn $1.63 \pm$ 1.008. Không có biến chứng nào được ghi nhận.

\section{BÀN LUÂ̂N}

Kéo dài trụ mũi là bước quan trong trong toàn bộ phẫu thuật tạo hình sửa các biến dạng môi mũi trên bệnh nhân di chứng khe hở môi vòm. ${ }^{1}$ Tăng chiểu dài trụ mũi giúp tăng rõ rệt độ nhô của mũi, yếu tố tạo nên sự thay đổi quan
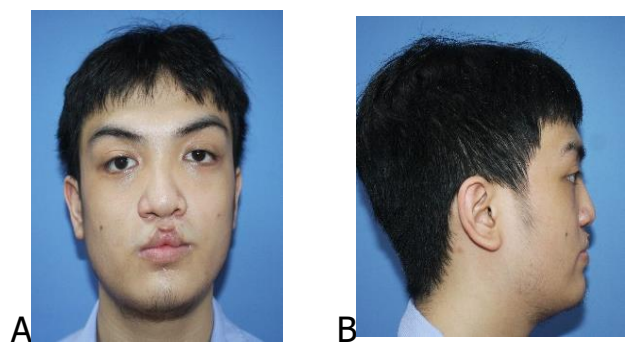

trọng về hình thể ngoài của mũi, cơ sở cho hiệu quả của các phương pháp đặt vật liệu dựng trụ và chỉnh sửa các biến dạng khung sụn mũi. Ngoài ra, kéo dài trụ mũi cũng góp phần cải thiện chiều dài của mũi. Kết quả của nghiên cứu cho thấy có sự cải thiện rõ rệt tỷ lệ chiều dài mũi/chiều dài tầng dưới mặt $(0.8 \rightarrow 0.876)$ (chiều dài tầng dưới mặt không thay đổi trước và sau phẫu thuât) và tỷ lê đô nhô mũi/chiều dài mũi $(0.46 \rightarrow 0.53)$. Tỳ lệ chiều cao môi trên/đô nhô mũi không giảm nhiều $(0.69 \rightarrow 0.65)$ dù độ nhô mũi tăng rõ rệt cho thây chiều cao môi trên ít bị ảnh hưởng, thậm chí được cải thiện gián tiếp thông qua các phương pháp kéo dài trụ mũi.

Có nhiều phương pháp có thể sử dụng cho mục đích kéo dài trụ mũi, chúng tôi lựa chọn phương pháp dựa trên những ưu, nhược điểm và sự phù hợp với các đặc điểm và mức độ biến dạng mũi khác nhau trong từng trường hợp.

Vat dồn đẩy dạng V-Y được biết đến như là "kỹ thuật Gensoul", được giới thiệu lần đầunăm 1833 [4]; được nhiều phẫu thuật viên sử dụng và cải tiến. Kỹ thuật có những hạn chế như: mức độ kéo dài trụ mũi không nhiêu; sẹo mổ ở đường giữa nhân trung; làmgiảm chiều ngang của môi trên. Trong nghiên cứu này vat $\mathrm{V}-\mathrm{Y}$ được chî̀ định trong các trường hợp thiếu chiều dài trụ mũi ít, nền mũi và cánh mũi 2 bên không quá rộng, hình thái của nhân trung và cung Cupid chấp nhận được, sẹo môi không cần can thiệp.

Vạt xoay đẩy của Millard là phương pháp lý tưởng để điều chỉnh các biến dạng thứ phát của khe hở môi một bên [5]. Vạt được chỉ định trên các bệnh nhân có tình trạng ngắn trụ mũi mức độ trung bình, ngắn chiều cao môi trắng và biến dạng cánh mũi trong di chứng khe hở môi một bển, Sẹo mổ thẩm mỹ trùng với viền nhân trung.
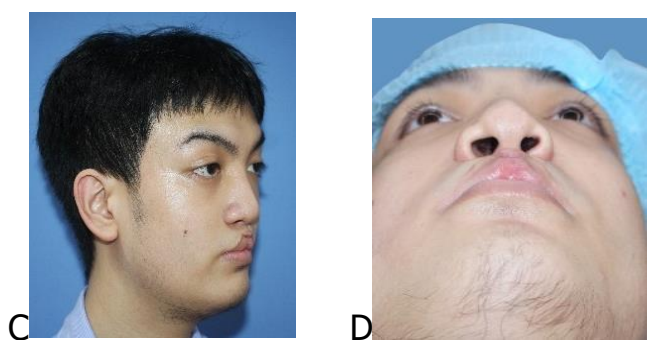

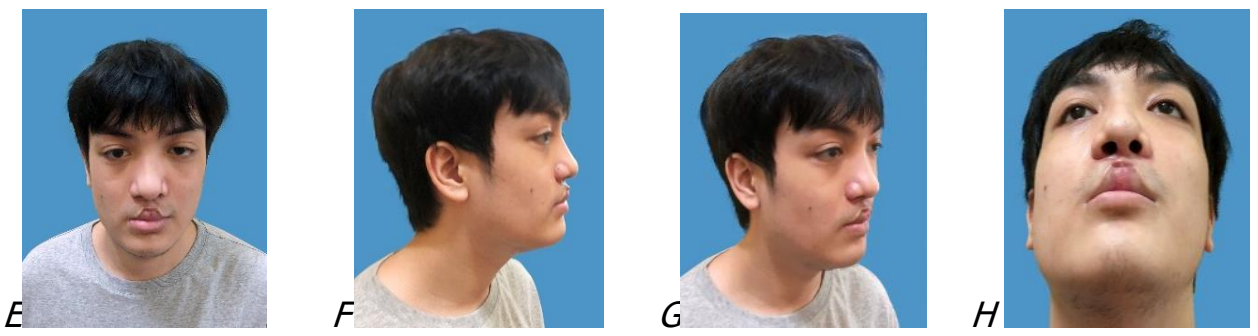

Hình 4. Tạo hinh mũi: nâng sống mũi với silicone, trụ mũi với Medpor, kéo dài

trụ mũi với vat folk, ghép sụn đầu mũi.

Trong phẫu thuật đóng khe hở môi, thông thường không có sự mất mát quá mức của mô vùng mỏm môi, thậm chí mỏm môi thường tăng kích thước rất nhiều dẫn đến có đủ mô để tạo ra một trụ mũi đủ dài. Millard [6](1958) đã sử dụng một vạt hai ngành từ các phần bên của mỏm mối bao gồm cả đường sẹo từ phẫu thuật môi trước đó để kéo dài trụ mũi. Forked flap, như được mô tả bởi Millard (1958) có những ưu điểm: Có đủ mô nơi cho từ phần bên của mỏm môi đáp ứng yêu cầu kéo dài trụ mũi; hầu hết bệnh nhân có khe hở môi hai bên cần chỉnh sửa sẹo môi và thu hẹp lỗ mũi sau lần phẫu thuật đầu tiên. Cả hai mục tiêu đó đều đạt được như là một phần của quá trình phẫu tích vạt và tạo đường vào thuận lợi cho chỉnh sửa cơ vòng môi cũng như sụn cánh mũi [1]. Thu hẹp môi ở phần trên dẫn đển sự dịch chuyển tự nhiên của phần dưới làm tăng chiều cao môi bằng cách để phần trung tâm còn lại của mấu môi dịch chuyển xuống dưới trong khi khâu lại. Vết sẹo để lại ở môi trên ở vị trí thẩm mỹ tương ứng với các gờ nhân trung. Hạn chế của kỹ thuật là nếu da được đóng lại theo mô tả ban đầu của Millard, các góc của năm vạt sẽ gần như gặp nhau tại điểm duy nhất ở gốc trụ mũi. Điều này có thể tạo ra một điểm yếu có thể xảy ra sự cố như hoại tử, thiểu dưỡng vạt, chậm liền thương. Đường sẹo dọc giữa trụ mũi hiếm khi cho kết quả thẩm mỹ khả quan. Forked flap được chúng tôi ưu tiên sử dụng trong trường hợp trụ mũi ngắn nhiều; mỏm môi rộng có chỉ định thu hẹp mỏm môi để tạo hình thái tự nhiên hơn của nhân trung; sẹo môi cần can thiệp sửa chữa; đồng thời mổi trên không quá cằng.

Vạt "Abbe" được Robbert Abbé giới thiệu là "vạt chuyển môi" vào năm 1898 để điều chỉnh thứ phát dị tật khe hở môi và vẫn được sử dụng rộng rãi cho đến nay. Vạt cung cấp chất liệu tạo hình tương đồng về màu sắc, chất lượng, toàn bộ tiểu đơn vị nhân trung được thiết kế lại, mang lại kết quả thẩm mỹ tốt [7]. Hạn chế của phương pháp là tạo ra một đường sẹo thẳng ở trung tâm môi dưới, sự gắn liền 2 mồi trong 2 tuần, khả năng gây ra những vết sẹo không thẩm mỹ [8]. Sử dụng vạt toàn bộ mấu môi để kéo dài trụ mũi kết hợp vạt Abbé trong trường hợp cần mức đô kéo dài trụ mũi lớn, môi trên căng và ngắn nhiều theo chiều dọc, khe tiền đình nông, sẹo môi xấu và thiếu tổ chức môi đỏ trung tâm.

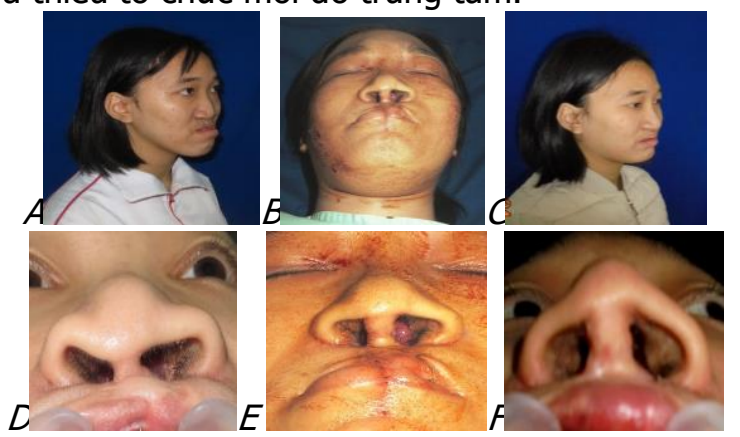

Hình 5. A, D. Biến dạng mũi di chứng khe hở môi toàn bộ hai bên. B,E. Sau phẫu thuật thi đầu tạo hinh mũi và tạo hinh nhân trung với vạt Abbe. C,F. Sau phẫu thuật 6 tháng.

\section{KẾT LUẬN}

Phương pháp tiếp cận kéo dài trụ mũi theo các cấp độ đã cho thây kết quả tốt, tỷ lệ bệnh nhân hài lòng cao và tỷ lệ biến chứng thấp.

\section{TÀI LIÊU THAM KHẢO}

1. G Eskeland, H Borchgrevink, F E Abyholm 1979. Columella lengthening in bilateral cleft lip patients. Experience with the forked flap procedure. Scand J Plast Reconstr Surg;13(3):42936. Doi:10.3109/02844317909013093.

2. Alsarraf $\mathbf{R}$. Outcomes Research in Facial Plastic Surgery: A Review and New Directions. Aesth. Plast. Surg. 24:192-197, 2000 DOI: $10.1007 / \mathrm{s} 002660010031$

3. Mortier P. B, Martinot L. V (1997), "Evaluation of the results of cleft lip and palate surgical treatment: Preliminary report", Cleft palatecraniofacial Journal, Vol 34 (3), 247- 254

4. Gensoul M. Reduction of a thickened columna and advancing the point of the nose. J Univ Hebd Med Prat 12:29, 1833.

5. Ying-jun Yan et al. Analysis of Millard II technique for correcting secondary deformities of unilateral cleft lip. Zhonghua Zheng Xing Wai Ke Za Zhi. 2006 May 
6. Millard Dr Jr. Columella lengthening by a forked flap. Plast Reconstr Surg 1958;42:535.

7. Abbe R. A new plastic operation for the relief of deformity due to double harelip. Plast Reconstr Surg 1968;42:481-3.
8. Lun-Jou Lo , Alex A Kane, Yu-Ray Chen. Simultaneous reconstruction of the secondary bilateral cleft lip and nasal deformity: Abbé flap revisited. Plast Reconstr Sur.2003 Oct;112(5) :1219-27.

\title{
NHẬN XÉT KẾT QUẢ THAY HUYẾT TƯƠNG TRONG PHỐI HỢP ĐIỀU TRI VIÊM TUỴ CẤP DO TĂNG TRIGLYCERIDE MÁU TẠI BỆNH VIỆN HỮU NGHI!
}

\author{
Tô Hoàng Dương*, Nguyễn Thế Anh*
}

\section{TÓM TẮT}

Mục tiêu: Mô tả các đặc điểm lâm sàng, cận lâm sàng và hiệu quả của liệu pháp thay huyết tương trong phối hợp điều trị viêm tuy cấp do tăng Triglyceride (TG). Đối tượng và phương pháp: 14 bệnh nhân được chẩn đoán viêm tuy có trị số TG> $11.3 \mathrm{mml} / \mathrm{L}$, được điều trị thay huyết tương phối hợp điều trị viêm tuỵ cấp thường quy tại khoa Hồi sức tích cực và Chống độc từ 2/2018 đến 2/2021. Tiến cứu mô tả. Kết quả: Giới nam: $78.6 \%$, nữ: $21.4 \%$; tuổi trung bình $62 \pm 17$; tiền sử: $64.3 \%$ uống rượu, $57.1 \%$ rối loạn lipid máu, $42.9 \%$ đái tháo đường. Thời điểm nhâp khoa; $100 \%$ đau bung trên rốn, $85.7 \%$ buồn nôn, nôn; $100 \%$ chướng bụng, $71.4 \%$ bí trung, đại tiên' $64,3 \%$ đau điểm sườn lưng. Chỉ số trung bình Amylase: $642 \pm 347 \mathrm{UI} / \mathrm{L}$, TG: $35.7 \pm 13.2 \mathrm{mmol} / \mathrm{L}$; Cholesterol: $13.7 \pm 4.2 \mathrm{mmol} / \mathrm{L}$. CT bung: $14.3 \%$ Baltaza E; 50\% Baltaza D; 35.7\% Baltaza C. Kết quả, thay huyết tương: $71.4 \%$ thay 01 lần; $21.4 \%$ thay 02 lần; $7.2 \%$ thay 03 lần. Dung dịch thay thế: $85.7 \%$ là plasma tươi và $14.3 \%$ làAlbumin $5 \%$. Nồng đô TG sau lọc lần 1: giảm từ 35.7 xuống 7.8; sau lần 2: 2.4 mmol/L. Biến chứng: $7.1 \%$ tắc quả $\mathrm{loc}, 7.1 \%$ tắc catheter, $14.3 \%$ dị ứng. Tỷ lệ khỏi: $92.9 \%$; tử vong $7.1 \%$. Kết luận:Thay huyết tướng là một liêu pháp an toàn và hiệu quả trong phối hợp điều trị viểm tuy cấp do tăng TGं; cân được triển khai rộng rãi và thường quy trong bệnh viện.

Tư khóa: Lâm sàng, cận lâm sàng, hiệu quả liệu pháp thay huyết tương, điều trị viêm tuỵ cấp.

\section{SUMMARY \\ COMMENT ON THE RESULTS OF PLASMA EXCHANGE IN COMBINATION TREATMENT FOR ACUTE PANCREATITIS DUE TO HYPERTRIGLYCERIDEMIA AT HUU NGH HOSPITAL}

Objective: To describe the clinical, subclinical, and clinical features of plasma replacement therapy in the combination treatment of triglyceride-induced pancreatitis (TG). Subjects and methods: 14

\section{*Bệnh viện Hữu Nghi}

Chịu trách nhiệm chính: Nghuyễn Thế Anh

Email: theanhhstc@gmail.com

Ngày nhận bài: 22/8/2021

Ngày phản biên khoa họ: 17/9/2021

Ngày duyệt bài: 2/10/2021 patients diagnosed with pancreatitis with TG value> $11.3 \mathrm{mml} / \mathrm{L}$, plasma exchange treatment combined with routine treatment of acute pancreatitis at the Intensive care and Control poisioning department from February 2018 to February 2021. Descriptive research. Results: Men: $78.6 \%$, women: $21.4 \%$; average age $62 \pm 17$; history: $64.3 \%$ drink alcohol, $57.1 \%$ have dyslipidemia, $42.9 \%$ diabetes mellitus. Time of admission; $100 \%$ abdominal pain on the navel, $85.7 \%$ nausea, vomiting; $100 \%$ bloating, $71.4 \%$ urinary retention, defecation; $64.3 \%$ of back pain point. Average Amylase index: $642 \pm 347 \mathrm{UI} / \mathrm{L}, \mathrm{TG}: 35.7 \pm$ $13.2 \mathrm{mmol} / \mathrm{L}$; Cholesterol: $13.7 \pm 4.2 \mathrm{mmol} / \mathrm{L}$. CT abdomen: $14.3 \%$ Baltaza E; $50 \%$ of Baltaza D; $35.7 \%$ Baltaza C. Results, plasma replacement: $71.4 \%$ instead of 01 time; $21.4 \%$ replaced 02 times; $7.2 \%$ changed 03 times. Alternative solution: $85.7 \%$ is fresh plasma and $14.3 \%$ is $5 \%$ albumin. The concentration of TG after the first filtration: decreased from 35.7 to 7.8; after 2nd time: $2.4 \mathrm{mmol} / \mathrm{L}$. Complications: $7.1 \%$ filter obstruction, $7.1 \%$ catheter obstruction, $14.3 \%$ allergies.Cure rate: $92.9 \%$; mortality $7.1 \%$. Conclusion: Plasma exchanged is a complete and effective treatment of conjunctivitis due to TG increase; should be widely and routinely deployed in the hospital.

Keywords: Clinical, subclinical, features of plasma replacement therapy, treatment of pancreatitis.

\section{I. ĐĂT VẤN ĐỀ}

Viêm tuy. cấp (VTC) là một quá trình tổn thương cấp tính của tuy, bệnh thường xảy ra đột ngột với những triệu chứng lâm sàng đa đạng, phức tạp từ VTC nhe thể phù đến VTC nặng thể hoại tử với các biến chứng suy đa tạng nặng nề, tî lệ tử vong cao. Ở Mỹ hằng năm có khoảng 250.000 trường hợp nhâp viên vì VTC; Ở Anh bênh nhân VTC tăng 3,1\% mỗi năm [1]. Khoảng $10-15 \%$ ca VTC có diến tiến nặng và có thể dẫn đến tử vong. Ở Việt Nam trong những năm gần đây qua một số nghiên cứu và thống kê cho VTC ngày càng gia tăng [2].

Có nhiều nguyên nhân gây ra VTC, đứng hàng đầu là do sỏi mật và nghiện rượu chiếm khoảng $80 \%$; tiếp sau đó là do tăng Triglyceride (TG), chiếm $1,3-3,8 \%$. Tuy nhiên, do chất lượng cuộc sống ngày một nâng cao, với chế độ ăn không hợp lý, các bệnh lý rối loạn chuyển hoá 